\title{
Notification of the Next Phase of Waiver Terminations in the Implementation of NRC Regulatory Authority for Certain Naturally Occurring and Accelerator-Produced Radioactive Material
}

\author{
Duane White
}

U.S. Nuclear Regulatory Commission, Office of Federal and State Materials and Environmental Management Programs, Washington, DC

$\mathbf{T}$ he Energy Policy Act of 2005 gave the U.S. Nuclear Regulatory Commission (NRC) authority over certain naturally occurring and accelerator-produced radioactive material (NARM). The NRC published its final rule implementing this authority in the Federal Register on October 1, 2007 (72 FR 55863). The final rule expanded the definition of "byproduct material" in NRC regulations and established requirements for licensing and regulating section 11e.(3) and 11e.(4) byproduct material, as required by section 651(e) of the Energy Policy Act. These final regulations became effective on November 30, 2007.

As authorized by section 651(e) of the Energy Policy Act, the NRC issued a waiver on August 31, 2005, to allow continued use and possession of NARM while the NRC developed a regulatory framework for regulation of the new byproduct material. The NRC is terminating the waiver in phases. On November 30, 2007, the NRC terminated the waiver for federal agencies, federally recognized Indian tribes, Delaware, the District of Columbia, Puerto Rico, the U.S. Virgin Islands, Indiana, Wyoming, and Montana. The NRC also terminated the waiver for all 34 agreement states that provided a certification from their governor to the NRC as described in the Energy Policy Act and the NRC's transition plan, which was published in the Federal Register on October 19, 2007 (72 FR 59157).

The NRC issued the second phase of waiver terminations on September 30, 2008. Vermont, West Virginia, Missouri, Idaho, South Dakota, Guam, and all territories and possessions of the United States that were not identified as part of the first phase of waiver terminations were included in the

\footnotetext{
Received Jan. 7, 2009; revision accepted Jan. 7, 2009.

For correspondence or reprints contact: Duane White, U.S. Nuclear

Regulatory Commission, Office of Federal and State Materials and

Environmental Management Programs, Washington, DC 20555-0001.

E-mail: Duane.White@nrc.gov.

COPYRIGHT @ 2009 by the Society of Nuclear Medicine, Inc.

DOI: $10.2967 /$ jnmt.109.061986
}

second phase. The timing and schedule for the second phase of waiver terminations was published in the Federal Register on March 18, 2008 (73 FR 14376). The agency anticipates that the waivers for the remaining non-agreement states-Connecticut, Virginia, New Jersey, Michigan, Alaska, and Hawaii-will be terminated in the third phase of the transition, which will occur on August 7, 2009. A notice in the Federal Register will be published approximately 6 mo before the effective date of the third phase of waiver terminations. Additionally, the NRC plans to terminate the waiver for non-agreement states that enter into an agreement with the NRC under section 274b of the Atomic Energy Act of 1954, as amended, coincident with the effective date of such an agreement. At this time, Pennsylvania is the only state that has become an agreement state before the second phase of waiver terminations.

On waiver termination, all persons who possess the new byproduct material in these states, U.S. territories, or areas of exclusive federal jurisdiction must be in compliance with the NRC regulations. However, the rule provides authorization for continued use of the new byproduct material before obtaining a license or license amendment, as long as applications are made within specified times. As provided in the transition plan, users of NARM in non-agreement states and U.S. territories will be required to apply for license amendments for the new byproduct material within 6 mo from the date the waiver is terminated, if they hold an NRC specific byproduct materials license, or submit a license application for the new byproduct material within 12 mo from the date the waiver is terminated for their state. NRC wants to remind users in the states affected by the first phase of waiver terminations that the date has passed for the submission of license amendments, which was to have occurred by May 30,2008 . Users in states affected by the first phase that still need to submit license amendments should submit their requests to the NRC as soon as possible. 
Those users in states affected by the second phase of waiver terminations must submit their license amendments by March 31, 2009, or their new license applications by September 30, 2009, to be in accordance with the time frame allotted in the transition plan.

Additional details about the implementation of the final rule on NARM can be found in the recent Regulatory Issue Summary 2008-13: Status and Plans for Implementation of NRC Authority for Certain Naturally Occurring and Accelerator-Produced Radioactive Material, issued on June 16, 2008 (http://nrc-stp.ornl.gov/narmtoolbox/ris2008-13. pdf). This summary updates the information contained in RIS 2007-22, dated October 4, 2007.

Also, NRC staff finalized revisions to the NUREG-1556 guidance for volume 9, "Program-Specific Guidance about
Medical Use Licenses"; volume 13, "Program-Specific Guidance about Commercial Radiopharmacy Licenses"; and the new volume 21, "Program-Specific Guidance about Possession Licenses for Production of Radioactive Materials Using an Accelerator." The NRC is also planning to make minor revisions, which reflect the regulation of NARM, to other NUREG-1556 licensing guidance and related inspection procedures. Furthermore, the NRC is preparing a set of frequently asked questions on ${ }^{226} \mathrm{Ra}$ that will be publicly available. The NRC has not yet finalized the schedule for completing these additional activities.

For more information on NARM-related activities, please go to the "NARM Toolbox" at the NRC's Office of Federal and State Materials and Environmental Management Programs Web site (http://nrc-stp.ornl.gov/narmtoolbox.html). 